\title{
ACERCA DE LA CREENCIA FILOSÓFICA EN EL MATERIALISMO
}

\author{
ENRIQUE VILLANUEVA \\ Universidad Nacional \\ Antónoma de México
}

En el número 26 de Crítica Carlos Ulises Moulines se confiesa no-materialista. Afortunadamente hay algo más que una confesión personal. Moulines exhibe una técnica filosófica inadecuada para tratar problemas como el del materialismo; sin embargo, debido a que la presentación de Moulines puede llevar a conclusiones erróneas, es menester aclarar la cuestión filosófica del materialismo.

Moulines supone un materialista "lego" para quien "sólo la materia existe". De lo que dice más adelante se desprende que dicho personaje encarna una postura frente al problema de la composición del mundo. Lo que este materialista lego sostiene es que el mundo está compuesto de materia y no de almas o de vacío, por ejemplo.

El propósito de Moulines reside entonces en mostrar al materialista lego que no conocemos lo que es la materia, porque los cuatro procedimientos para decidir lo que ésta sea no nos dan ese conocimiento o bien nos dicen que la materia es algo que el materialista lego o "normal" no puede o no debe aceptar como tal. Del fracaso de esta búsqueda Moulines deriva una conclusión mucho mas ambiciosa, a saber, que debemos aceptar un punto de vista pluralístico acerca de la composición del universo porque no hay un predicado empírico simple "materia", que se aplique a la totalidad de lo que hay en el universo.

En suma, Moulines piensa que no hay una teoría general, absoluta, esencialista acerca de la materia y por ello debemos rechazar el materialismo. Su argumento en favor de esta conclusión consiste en mostrar que la evidencia que nos pro- 
porciona la investigación de la física no nos da un concepto de materia que se aplique a la totalidad del mundo y que satisfaga las instituciones del materialista lego. Veamos.

Moulines dice -en primer lugar- que no conocemos lo que es la materia porque la física de las partículas no se atreve a pronunciarse sobre el particular. Moulines parece sostener un realismo tajante: la materia es algo y la investigación física es la autoridad que determina la conceptuación de ese algo. Pero esto equivale a poner la carreta antes de los bueyes. Nosotros tenemos un concepto de materia que el filósofo debe elucidar y el físico debe investigar empíricamente.

La tesis de Moulines es muy fuerte y exige argumentos mucho más sólidos que los aducidos por él.

En segundo lugar, ante la proposición de que el sentido común determine lo que es la materia, Moulines afirma que la empresa debe desembocar en el idealismo subjetivo à la Descartes o en un espiritualismo à la Leibniz. Desgraciadamente Moulines tampoco ofrece argumentos en favor de estas afirmaciones. Es dudoso que en la historia filosófica esto haya sido asi, pero claramente no tiene por qué serlo. Los sentidos son una forma de nuestro acceso a la materia y no una parte constitutiva de la misma. En esto se equivocaron Berkeley y otros cartesianos. De manera similar, la conceptuación externo-interno no tiene por qué llevarnos al dualismo de las sustancias y, en fin, tampoco necesitamos caer en el sofisticado sistema de las mónadas de Leibniz. Hay elucidaciones contemporáneas del concepto de sustancia material que representan enemigos de consideración y a los cuales no atiende Moulines. Tal es el caso del trabajo de P. F. Strawson y de A. Quinton.

El tercer candidato, la interpretación atomista, y el cuarto, la teoría general de la relatividad, tampoco satisfacen a Moulines. Respecto a esta última dice que aporta una concepción demasiado geométrica de la materia, inaceptable para el materialista normal. Pero no da razones por las que dicho materialista tenga que rechazar tal interpretación, ni 
elucida el concepto de materia o las intuiciones que maneja ese materialista normal. En verdad, no hay un enemigo determinado y sobre todo, no hay un filósofo enemigo determinado.

¿Qué materialista tiene en mente Moulines? ¿Es el hombre de la calle con sus prejuicios y fantasías? ¿Se trata de un enemigo imaginario construído ad hoc? ¿Quizá quiera aludir a alguno de nuestros materialistas locales? En verdad las consideraciones de Moulines constituyen un reto para lo que esos materialistas locales dicen creer. $\mathrm{Y}$ esto, aún cuando útil y conveniente en nuestro medio, no toca la cuestión filosófica del materialismo.

Creo que Moulines distorsiona dicha cuestión en una forma característica: a saber, pregunta por la evidencia -la cual constituye la cuestión científica-, olvidando que, si hay una cuestión filosófica, ésta debe ser previa a las cuestiones de prueba o evidencia. Se debe tratar de una cuestión conceptual, para ponerle un nombre. Y éste es el trabajo que han hecho personas como Aristóteles, Kant y en nuestros días Strawson. Uno de estos filósofos no se plantea la cuestión "¿qué evidencia (científica) tenemos para decir que la materia es $X$ o $Y$ ?" como tampoco discurre consultar las publicaciones recientes de física para ver cuál es la última definición de materia que se propone allí.

Moulines dice que "materia" es un predicado empírico simple pero vacuo, porque no está restringido por condiciones empíricas. Esta tesis es muy fuerte y necesita argumentarse más. Moulines no aclara si esa vacuidad es irremediable ni si impide introducir la creencia materialista en otra forma. En suma, no expone el argumento ni determina los alcances del mismo.

¿Qué decir del materialista? Bueno, hay muchos tipos de materialistas que dicen cosas muy diferentes. Moulines no aclara esto ni hace justicia a las intuiciones de los materialistas. Vale la pena traer a colación una forma paradigmática de abordar el materialismo. En el problema de la mente y el cuerpo, por ejemplo, se llega al materialismo en una for- 
ma oblicua pero no por ello carente de fuerza. Lo que un filósofo se plantea a este respecto es la cuestión acerca del hecho de la conciencia. Dado que tenemos conciencia ¿qué hacer con ella? ¿Debemos considerarla como algo independiente y opuesto a la actividad cerebral? ¿Nos obliga esto último a aceptar una ciencia autónoma de lo mental? Los filósofos materialistas tratan de hacer posible y plausible la creencia de que la conciencia no es un hecho último, y en esta forma dan contenido a la proposición "sólo la materia existe". Esta empresa no es fácil y así lo demuestra el trabajo enorme y a veces sutil en el análisis de los conceptos mentales, en las teorías de la referencia y de la identidad que hacen plausible y quizá posible la tesis materialista.

Tampoco es claro si Moulines desea afirmar que el materialismo es implausible, falso o ininteligible, pero cualquiera que sea su acusación, debe tener en cuenta esas formas de llegar a la tesis materialista. El sentido del materialismo filosófico incluye oscuridades y una fascinación radicalmente importantes a las que hay que hacer justicia antes de confesarse no-materialista.

El propósito del trabajo de Moulines es didáctico, como lo es también el mío. La manera que utiliza Moulines para desacreditar la creencia en el materialismo no es fecunda. Moulines desea extirpar un prejuicio vulgar y dejar abierto el camino para sostener ciertas creencias metodológicas y vitales - creencias estas últimas que conciernen a nuestra actividad pública y privada. Este propósito bien puede implicar el rechazo de varias interpretaciones ingenuas de que "todo es materia", pero no de una creencia filosófica por demás respetable y genuina.

El materialista al que se opone Moulines es, en verdad, un lego; pero, sobre todo, no es un filósofo. Moulines nos participa su enfático rechazo del materialismo vulgar de los legos; ahora debemos esperar a que nos presente sus sólidos y demoledores argumentos en contra del materialismo de los filósofos. 